\title{
Enhanced Prophylactic and Therapeutic Effects of Polylysine-Modified Ara h 2 DNA Vaccine in a Mouse Model of Peanut Allergy
}

\author{
Zhenlai Zhu ${ }^{\mathrm{a}}$ Jinlei Yu ${ }^{\mathrm{a}}$ Yuan Niu ${ }^{\mathrm{a}}$ Shuhong Sun ${ }^{\mathrm{a}}$ Yufeng Liu ${ }^{\mathrm{a}}$ \\ Andrew Saxon ${ }^{\mathrm{b}}$ Ke Zhang ${ }^{\mathrm{a}}$, Wei Li $^{\mathrm{a}-\mathrm{c}}$ \\ ${ }^{a}$ Department of Dermatology, Xijing Hospital, Fourth Military Medical University, Xi'an, PR China; \\ ${ }^{b}$ Hart and Louise Lyon Immunology Laboratory, Section of Clinical Immunology/Allergy, Division of Pulmonary, \\ Critical Care and Clinical Immunology/Allergy, Department of Medicine, David Geffen School of Medicine at UCLA, \\ Los Angeles, CA, USA; 'Department of Dermatology, Huashan Hospital, Fudan University, Shanghai, PR China
}

\section{Keywords}

Allergy vaccines · Animal models · Ara h $2 \cdot$ Peanut allergy · Polylysine $\cdot$ Regulatory T cells

\begin{abstract}
Background: The prevalence of food allergy has been increasing, but treatment is very limited. DNA vaccination has been recognized as a promising method for the treatment of allergic diseases; however, poor immunogenicity has hindered its application. Methods: BALB/c mice were intradermally injected with plasmid DNA encoding the peanut protein Ara h 2 (pAra h 2) or pAra h 2 pretreated with poly-Llysine (PLL) before or after sensitization with Ara $\mathrm{h} 2$ protein. Ara $\mathrm{h}$ 2-specific antibodies were measured by ELISA. CD207+ dendritic cells (DCs) and Treg cells in draining lymph nodes were analyzed by flow cytometry after DNA immunization, and cytokine production in splenocytes was also analyzed. Results: In the prophylactic study, pretreatment with pAra $\mathrm{h}$ 2 or PLL-pAra h 2 resulted in lower levels of Ara h 2-specific $\lg \mathrm{g} 1, \lg \mathrm{G} 2 \mathrm{a}$, and $\lg \mathrm{E}$ after sensitization with Ara $\mathrm{h} 2$ protein, and mice in the PLL-pAra $h 2$ group had a significantly lower level of antibodies than those in the pAra $\mathrm{h} 2$ group. In the treatment study, intradermal injection with pAra h 2 or PLL-
\end{abstract}

\section{KARGER}

() 2017 S. Karger AG, Basel

E-Mail karger@karger.com

www.karger.com/iaa
pAra h 2 after Ara h 2 protein sensitization significantly decreased the level of Ara h 2-specific antibodies, and PLLpAra $h 2$ had stronger effects than pAra $h$ 2. There were increased numbers of CD207+ DCs and Treg cells in the mice receiving intradermal injection with PLL-pAra $\mathrm{h} 2$, and splenocytes from PLL-pAra h 2-treated mice secreted increased levels of IFN- $\gamma$ and IL-10. Conclusions: Modification of pAra h 2 with PLL improved its prophylactic and therapeutic effects in peanut-allergic mice.

(c) 2017 S. Karger AG, Basel

\section{Introduction}

Peanut allergy, an epidemic allergic disease, is an adverse immunologic response to peanut allergens which is potentially life-threatening. It is estimated that $1.2-1.5 \%$ of individuals in Europe are affected with peanut allergy [1]. Subcutaneous immunotherapy with crude peanut extracts (CPEs) was eliminated from treatment options due

Correspondence to: Dr. Wei Li

Department of Dermatology, Xijing Hospital

127 Changlexi Road

Xi'an, Shaanxi 710032 (PR China)

E-Mail liweil @fmmu.edu.cn

Co-corresponding author: Dr. Ke Zhang

37-131 CHS, David Geffen School of Medicine at UCLA

10833 Le Conte Avenue

Los Angeles, CA 90095-1690 (USA)

E-Mail sixalinc@gmail.com 
to its severe side effects [2]. However, until now, the only approved treatments are avoidance of the allergenic food and administration of emergency medications on accidental exposure. The newly developed oral immunotherapy showed high efficacy and opened a new age for the treatment of food allergy [3]. Recent landmark research showed that when infants at high risk of developing peanut allergy consume peanuts on a regular basis, their risk can be dramatically reduced [4]. Furthermore, the prevalence of peanut allergy is not increased after a 1-year period of peanut avoidance following peanut consumption in infants at high risk for peanut allergy [5]. These studies have changed the care of children at high risk for peanut allergy. However, both subcutaneous immunotherapy and oral immunotherapy are accompanied by a lack of sustained protection and an increased risk of both systemic reactions and intolerable gastrointestinal symptoms [2]. For severe food allergy, both subcutaneous immunotherapy and oral immunotherapy are very dangerous, as trace amounts of peanut allergen would lead to anaphylaxis. Preclinical studies indicated that allergen applied through epicutaneous immunotherapy to intact skin activates antigen-presenting cells (APCs) in the skin to affect immune responses while avoiding systemic reactions [6]. Recently, epicutaneous immunotherapy, such as the new Viaskin Peanut patch (DBV Technologies, Bagneux, France) showed promising results in a phase I study [7].

The allergen gene vaccination can modulate allergic responses and represents a promising alternative to the protein-based allergen-specific immunotherapy in terms of safety and efficacy as this approach has been shown to be safe and effective in the inhibition of allergen-specific IgE production and suppression of Th2 responses [8]. Allergen genes have been administered as naked plasmid DNA by various routes, including intramuscular or intradermal injection [9], biolistic transfection via gene gun [10], or orally as plasmid DNA-polymer complexes [11]. DNA immunization has been shown to be effective in inhibiting the development of antigen-specific IgE production $[8,9,12]$. Early studies demonstrated DNA vaccine encoding allergen through inducing a shift from a Th2type response towards a Th1-biased response [9, 13, 14]. Recently, several studies demonstrated that DNA vaccine may provide protective and therapeutic effects through inducing Treg cells $[15,16]$. Despite the anti-allergy effects observed in mice and other small rodents, DNA vaccines showed relatively low immunogenicity in humans when compared to protein vaccines [17]. Poor immunogenicity becomes the biggest obstacle for DNA vaccine to treat and prevent allergic diseases in humans. Therefore, it is an urgent requirement to find effective DNA delivery strategies to enhance the potency of DNA vaccines.

There are various strategies for modifying the immune efficiency of a DNA vaccine, such as physical methods and modifications by synthesized polymers [18]. We previously produced a recombination protein of $\varepsilon$ immunoglobulin heavy chain fused with PLL selectively targeting the allergen gene to human dendritic cells (DCs) [19]. PLL can electrostatically bind the negatively charged DNA and has extensively been used in drug delivery [20]. Since PLL is not only water soluble and biodegradable but can also prevent conjugated DNA from nuclease degradation and increase the transport efficiency of DNA, it has been shown to be an effective gene vector which makes DNA absorption easy, is presented by APCs, and improves the immunogenicity of DNA vaccine. However, PLL-modified food allergen genes, especially peanut allergen gene vaccine, have not been reported.

In the present study, we assessed the prophylactic and therapeutic effects of PLL-pretreated DNA vaccine which encodes the major peanut allergen Ara $\mathrm{h} 2$ and found that PLL-modified DNA vaccine effectively inhibited the development of Ara h 2-induced allergen-specific antibodies and also decreased the level of established allergen-specific antibodies in Ara $\mathrm{h} 2$-sensitized mice. Immunization with PLL-modified DNA vaccine induced enhanced accumulation of CD207+ and Treg cells in the draining lymph nodes (dLNs) and also increased the production of IFN- $\gamma$ and IL-10 by splenocytes. Thus, our study provided a foundation for further clinical research on the application of DNA vaccine for the treatment of peanut allergy.

\section{Materials and Methods}

Mice

Specific pathogen-free, 6- to 8-week-old female BALB/c mice were obtained from a local breeding facility at the Fourth Military Medical University. CD207(langerin)-EGFP mice were purchased from Jackson Laboratory. All mice were maintained under specific pathogen-free and controlled conditions $\left(22^{\circ} \mathrm{C}, 55 \%\right.$ humidity, and 12-h day/night rhythm). The animal experiments were performed in compliance with the guidelines outlined in the Guide for the Care and Use of Laboratory Animals of the University.

Purification of Ara $h 2$ Plasmid and Preparation of pAra $h 2$

Vaccine Pretreated with PLL

The plasmid of pAra h 2 was developed previously by our group by inserting the cloned wild-type Ara $\mathrm{h} 2$ gene into the pcDNA3.1 plasmid containing the CMV promoter. The plasmid was confirmed by restriction enzyme digestion analysis with HindIII and 
ApaI. Large-scale purification of the plasmid pAra h 2 was conducted by using EndoFree Plasmid Maxi kits (Qiagen, USA) according to the manufacturer's instructions. The plasmid was mixed with different proportions of PLL (molecular weight 15,000-30,000; Sigma) in $0.15 \mathrm{M} \mathrm{NaCl}$ and was analyzed by electrophoresis. Then, an appropriate concentration of PLL was used for the following experiments.

\section{CPE Preparation}

CPEs were prepared according to published protocols $[21,22]$. Protein concentrations were determined with the BCA kit (Qiagen) using BSA as the standard.

\section{Mouse Immunization and Challenge}

The experimental design to evaluate the prophylactic effect of the vaccine was shown in Figure $2 \mathrm{a}$. Mice were injected intradermally with PLL-pAra h 2 or pAra h 2 vaccine containing $25 \mu \mathrm{g}$ pAra h 2 DNA for 3 times at weekly intervals, with PBS, PLL, or mock DNA as control. The mice were then intraperitoneally injected with a mixture of $2.5 \mu \mathrm{g}$ purified Ara h 2 protein (Indoor Biotechnologies, Charlottesville, VA, USA) and $1 \mathrm{mg}$ aluminum hydroxide gelatin (Sigma) in a total volume of $100 \mu \mathrm{l}$ sterile PBS for 3 times. The design to evaluate the therapeutic effects of the DNA vaccine was shown in Figure 3a. Mice were sensitized first by intraperitoneal injection with $2.5 \mu \mathrm{g}$ purified Ara h 2 protein and $1 \mathrm{mg}$ aluminum hydroxide gelatin, followed by treatment with different formulations of DNA vaccine. Blood was taken at the indicated time points and subjected to allergen-specific antibody analysis. For challenge experiments, the symptoms of anaphylaxis were monitored by measuring the rectal temperature after intraperitoneal injection with $5 \mathrm{mg} \mathrm{CPE}$.

\section{Measurement of Serum Ara h 2-Specific IgG1 or IgG2a and}

Total IgE

The levels of Ara h 2-specific IgG1, IgG2a, and total IgE were analyzed with enzyme-linked immunosorbent assay (ELISA) as previously described [23] with modifications. To measure Ara h 2-specific IgG1 and IgG2a, ELISA plates (Nunc, Nalgene Nunc International, Roskilde, Denmark) were coated overnight with purified Ara h 2 proteins $(2 \mu \mathrm{g} / \mathrm{mL}$; Indoor Biotechnologies $)$ at $4^{\circ} \mathrm{C}$ overnight. To detect total IgE, purified rat anti-mouse IgE $(2 \mu \mathrm{g} /$ $\mathrm{mL}$; BD Pharmingen) was used for coating. Following blocking, serum was diluted and incubated at room temperature for $2 \mathrm{~h}$. Subsequently, biotin-conjugated rat anti-mouse IgG1, IgG2a, or IgE (all from BD Pharmingen) were incubated for another $2 \mathrm{~h}$. After extensive washing, horseradish peroxidase-conjugated avidin (Biolegend, San Diego, CA, USA) was added and incubated for $1 \mathrm{~h}$ at room temperature. Finally, after extensive washing, TMB (Solarbio Life Science) was added and incubated for 5-20 min, and the reaction was stopped with $1 \mathrm{M} \mathrm{H}_{2} \mathrm{SO}_{4}$. The optical density was measured at $450 \mathrm{~nm}$. The Ig titers were determined by comparing a reference serum with arbitrary titer.

\section{Cell Culture and in vitro Cytokine Production}

$\mathrm{BALB} / \mathrm{c}$ mice were given 3-weekly intradermal injections of PBS, PLL, mock DNA, pAra h 2, PLL-pAra h 2, or Ara h 2. Three days after the last immunization, mouse dLNs and spleen were harvested, and single-cell suspensions were made as previously described [24]. Then splenocytes were stimulated with $5 \mu \mathrm{g} / \mathrm{mL}$ Ara h 2 . Supernatants were harvested after $96 \mathrm{~h}$ of culture and stored

Polylysine-Modified Ara h 2 DNA

Vaccine for Peanut Allergy

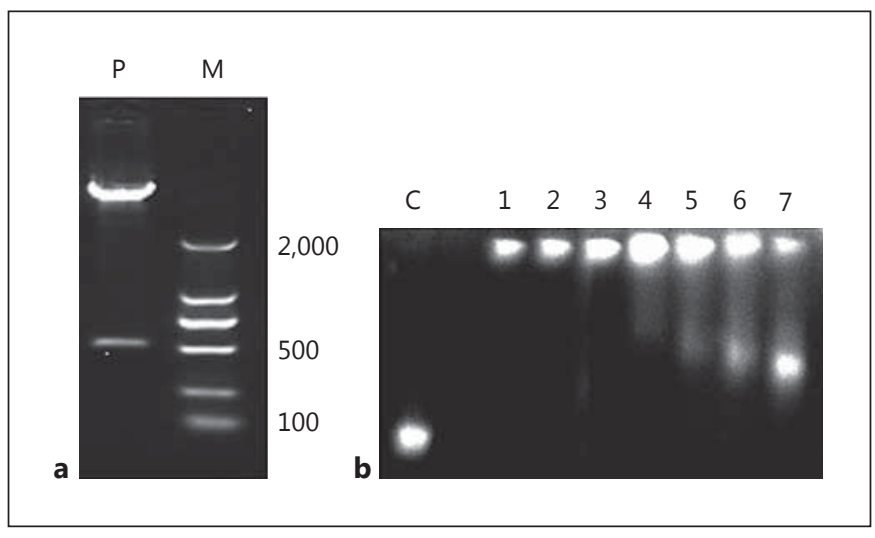

Fig. 1. Preparation of pAra h 2 and PLL-pAra h 2. a The plasmid pAra h 2 containing the Ara h 2 gene was digested with HindIII and ApaI and analyzed by electrophoresis. (P, pAra h 2; M, marker). b Serial dilution of $10 \mu \mathrm{L}(5 \mu \mathrm{g} / \mu \mathrm{L})$ PLL $(1: 80,1: 120 ; 1: 160$, $1: 200,1: 240,1: 280,1: 320$ for lanes $1-7$, and $C$ for pAra $h 2$ control) were mixed with $1 \mu \mathrm{L}$ of $7 \mu \mathrm{g} / \mu \mathrm{L}$ pAra h 2 and analyzed by electrophoresis.

at $-80^{\circ} \mathrm{C}$. Cytokines, including IL-4, IL-5, IL-10, IL-22, and IFN- $\gamma$, were determined by ELISA according to manufacturer's instructions (R\&D, Minneapolis, MN, USA).

\section{Flow Cytometry}

Single-cell suspensions prepared from dLNs were stained with anti-CD11b (clone M1/70; Biolegend) antibodies and subjected to FACSCalibur analysis. 7-AAD (Biolegend) was used to exclude dead cells. The CD4+CD25+Foxp3+ Tregs in the dLNs and spleen were analyzed with a Treg cell detection kit (Biolegend) and analyzed by FACS. The data were analyzed with FlowJo software (Tree Star).

\section{Data Analysis}

Data are presented as means $\pm \mathrm{SD}$, and statistical analyses were performed using ANOVA with the Tukey multiple-comparison post hoc test or $t$ test. A statistically significant difference was defined as $p<0.05$, which was indicated with 1 asterisk, and 2 asterisks indicated that the $p$ value was below 0.01 .

\section{Results}

Preparation of PLL-Modified pAra $h 2$ Vaccine and Establishment of Ara h 2-Induced Peanut Allergy

Previously, we tested the idea of PLL-modified DNA vaccine targeting DCs and found that PLL fused with the Fc fragment of IgE (EPL) could bind to DNA [19] and target the IgE receptor expressed on APCs. However, the major hurdle of the strategy of EPL-DNA is that the EPLDNA complex might crosslink the IgE receptor expressed on mast cells and elicit degranulation. Thus, in the pres- 


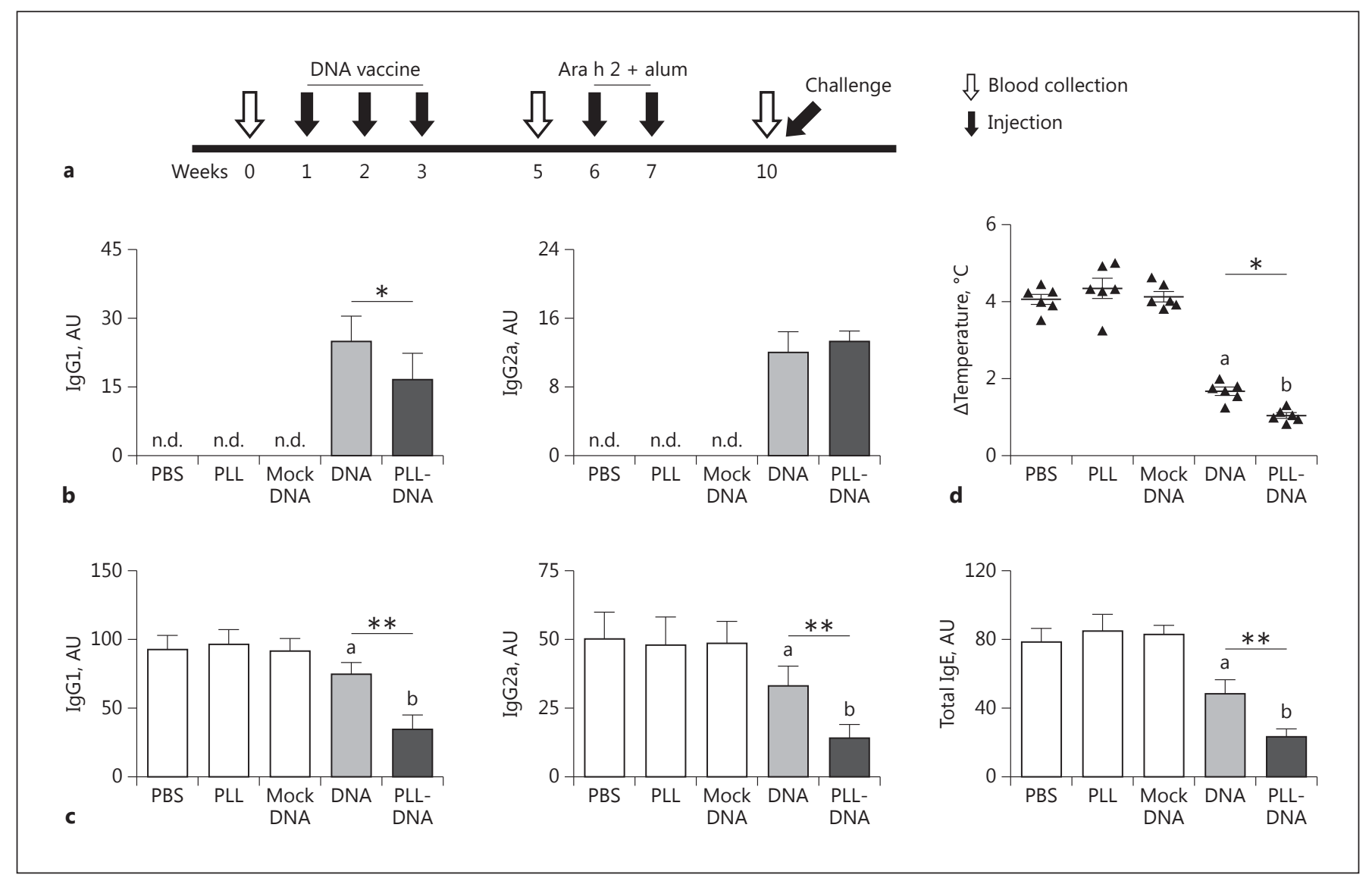

Fig. 2. PLL modification enhanced the prophylactic effects of pAra h 2 vaccine. a Scheme of the prophylactic experiment. b ELISA results of Ara h 2-specific IgG1 and IgG2a at week 5. c ELISA results of Ara h 2-specific IgG1, IgG2a, and total IgE at week 10. d Changes in rectal temperature at different time points after CPE challenge. Data represent 1 of 3 independent experiments. Means $\pm \operatorname{SD}\left(n=6\right.$ for each group). ${ }^{*} p<0.05,{ }^{* *} p<0.01$, vs. PBS, PLL, or mock DNA group.

ent study, we just tested the effects of PLL-modified DNA vaccine on peanut allergy. Firstly, we prepared the PLLDNA complex. The fragment of the plasmid DNA encoding Ara h 2 was confirmed by restriction enzyme digestion (Fig. 1a). To obtain a proper polymerization of PLLDNA, we screened the extent of polymerization by mixing different doses of PLL with a certain amount of DNA and subsequent analysis by electrophoresis. The optimum amount of PLL was found to be the one which mixed 0.2 $\mu \mathrm{g}$ of PLL with $7 \mu \mathrm{g}$ pAra h 2 in $0.15 \mathrm{M} \mathrm{NaCl}$ solution (Fig. 1b; lane 6). To produce the mouse model of peanut allergy, we injected intraperitoneally purified peanut protein Ara h 2 which was mixed with alum to BALB/c mice for 2 times with a 1-week interval. Three weeks after the last injection, sera from the injected mice were collected and subjected for ELISA analysis. It was found that the levels of Ara h 2-specific IgG1, IgG2a, and total IgE (online suppl. Fig. S1a; for all online suppl. material, see www.karger.com/doi/10.1159/000453264) were significantly increased in Ara h 2-sensitized mice but not in unsensitized mice. We found that there was almost no total IgE detectable in the mouse serum before Ara $\mathrm{h} 2$ protein sensitization, and the total IgE was well correlated with the antigen-specific IgE antibodies [24]. Thus, we used total IgE, instead of antigen-specific IgE, to monitor the effects of DNA and protein immunization. Then, we challenged the mice by intraperitoneal injection with CPEs and found that systemic anaphylaxis was induced as evidenced by greatly decreased rectal temperature in the following $60 \mathrm{~min}$ (online suppl. Fig. S1b), confirming the peanut protein-mediated allergy in Ara $\mathrm{h} 2$ protein-sensitized mice. 


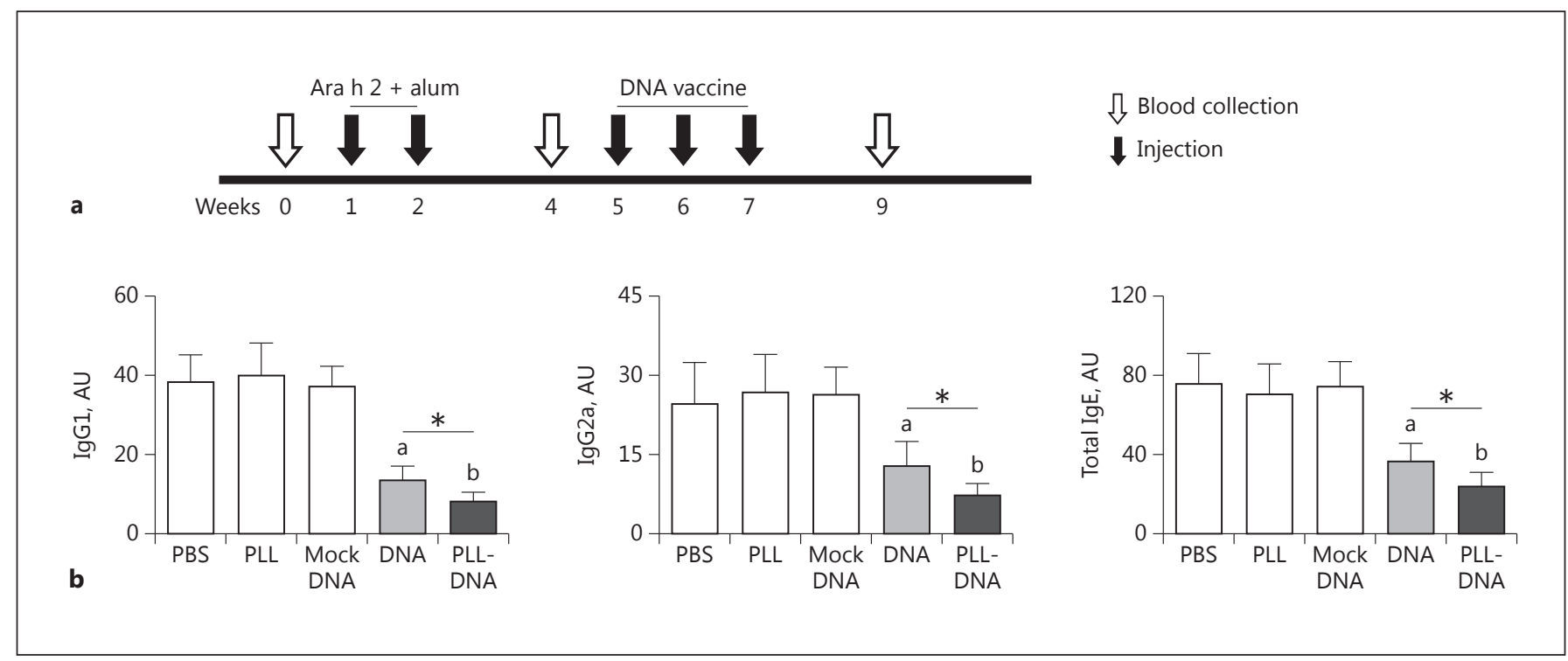

Fig. 3. Amelioration of established peanut allergy after PLL-pAra h 2 treatment. a Therapeutic protocol of DNA vaccine. b ELISA results of Ara h 2-specific IgG1 and IgG2a, and total IgE at week 9. Data represent 1 of 3 independent experiments. Means $\pm \mathrm{SD}$ ( $n=6$ for each group). ${ }^{*} p<0.05$, vs. PBS, PLL, or mock DNA.

PLL Modification Improved the Prophylactic Effects of pAra 2 Vaccine in Peanut Allergy

To evaluate the prophylactic effect of the pAra h 2 vaccine, BALB/c mice were firstly injected intradermally for 3 times with $25 \mu \mathrm{g}$ pAra h 2 plasmid or $25 \mu \mathrm{g}$ pAra h 2 DNA premixed with PLL, and then subjected to sensitization with Ara $\mathrm{h} 2$ protein plus alum, according to the prophylactic protocol (Fig. 2a). Two weeks after the last injection with DNA vaccine, there were slightly increased levels of Ara h 2-specific IgG1 and IgG2a, but not IgE, in the sera of mice receiving pAra h 2 or PLL-pAra h 2 immunization (Fig. 2b). After intraperitoneal sensitization with Ara h 2 protein, Ara h 2-specific IgG1, IgG2a, and total IgE in the sera were analyzed at week 10 , and the results showed that there were significantly increased levels of Ara h 2-specific IgG1, IgG2a, and total IgE in the control mice pretreated with PBS, PLL, or mock DNA (Fig. 2c); however, the mice receiving intradermal injections of pAra h 2 or PLL-pAra h 2 showed significantly lower antibody responses, and the PLL-pAra h 2-pretreated mice had even lower levels of Ara h 2-specific antibodies compared to pAra h 2-pretreated mice (Fig. 2c). In the challenge assay, the kinetics of core body temperature reflecting systemic anaphylaxis was monitored after intraperitoneal injection of CPEs, and the results showed that the core body temperature of PLL-pAra h 2 or pAra h 2-pretreated mice did not change significantly after

Polylysine-Modified Ara h 2 DNA

Vaccine for Peanut Allergy challenge (Fig. $2 \mathrm{~d}$ ). In contrast, the challenge with CPEs markedly decreased the core body temperature in control mice (Fig. 2d). These data demonstrated that pAra h 2 vaccine, especially the PLL-pAra $h 2$ vaccine, prevented CPE-induced anaphylactic manifestations, confirming the prophylactic effect of the vaccine.

\section{PLL-pAra h 2 Vaccine Had Better Therapeutic Effects} than pAra $h 2$ on Established Peanut Allergy

Next, we set out to investigate whether pAra h 2 vaccine could also have therapeutic effects and whether PLL modification could enhance the effects of pAra $h 2$. $\mathrm{BALB} / \mathrm{c}$ mice were firstly sensitized intraperitoneally with Ara $\mathrm{h} 2$ protein plus alum and then injected intradermally with pAra $h 2$ or PLL-pAra $h 2$ according to the therapeutic protocol (Fig. 3a). The levels of Ara h 2-specific IgG1, IgG2a, and total IgE were analyzed by ELISA at the indicated time points. All groups of mice showed increased levels of Ara h 2-specific IgG1, IgG2a, and total IgE in week 4 after Ara h 2 protein sensitization (data not shown). After 3 injections with DNA vaccine, the levels of Ara h 2-specific IgG1, IgG2a, and total IgE were significantly decreased in pAra h 2 and PLL-pAra h 2 groups, which were lower than that of control groups (PBS, PLL, or mock DNA), and, in the PLL-pAra h 2 group, the titer of antibodies was even lower than that of the pAra h 2 group (Fig. 3b). Thus, it is suggested that 


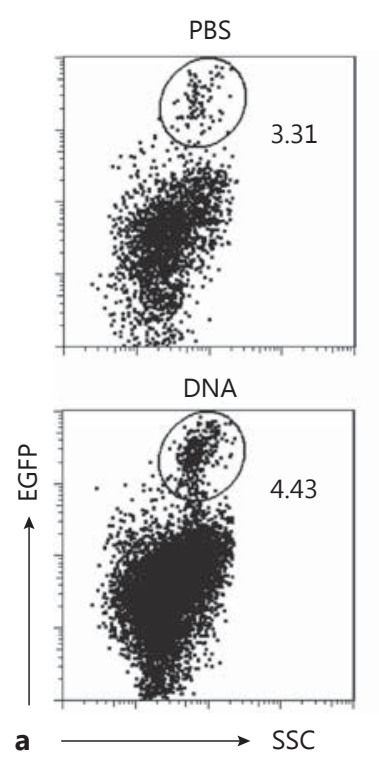

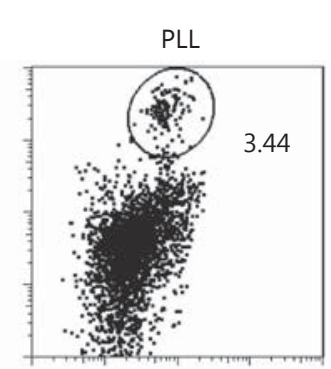
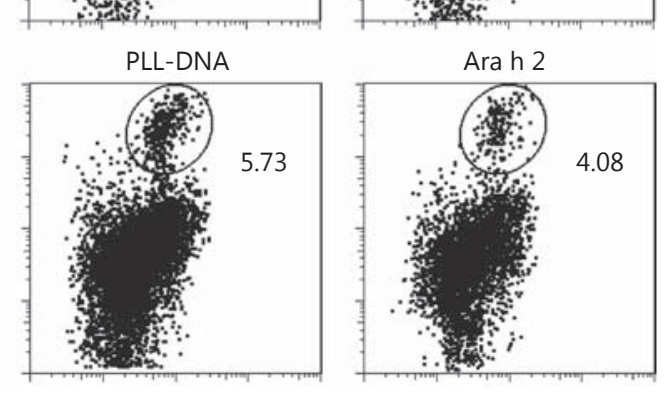

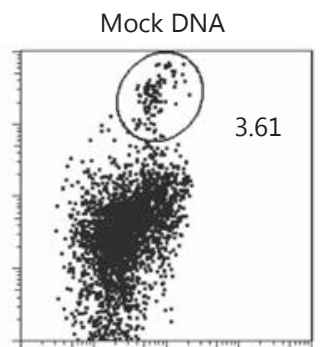

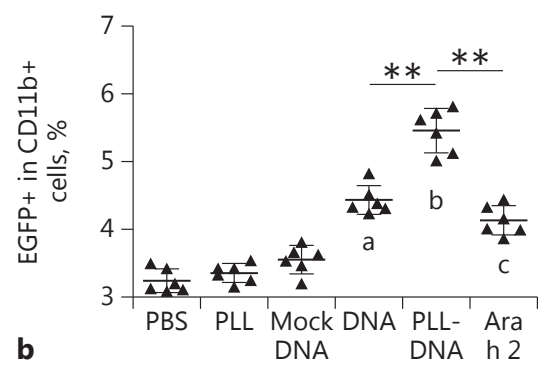

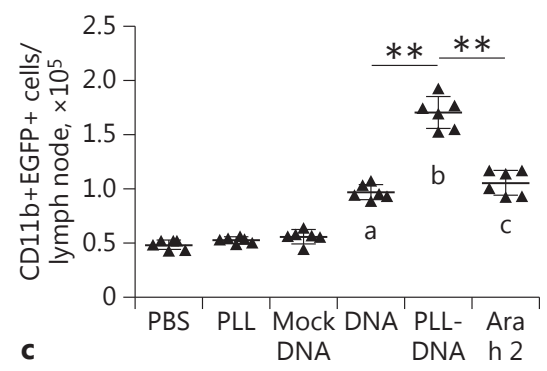

Fig. 4. CD207+ DCs in skin dLNs after DNA vaccine immunization. CD207-EGFP mice were given 3 weekly intradermal injections with PBS, PLL, mock DNA, DNA, PLL-DNA, or Ara h 2 protein, and 3 days after the last immunization, cells from skin dLNs were prepared, stained with antibodies, and analyzed by FACS. a Representative FACS results showing EGFP+ cells gated from CD11b+ cells in dLNs. b Statistic results of the relative numbers of EGFP+ cells gated from CD11b+ cells. c Absolute numbers of CD11b+EGFP+ cells in dLNs. Pooled from 2 independent experiments (total $n=6$ ). Means \pm SD. ${ }^{* *} p<0.01$, vs. PBS, PLL, or mock DNA. the DNA vaccine, especially PLL-pAra $\mathrm{h}$ 2, was able to modulate the established Ara h 2-induced immune responses and showed therapeutic effects on peanut allergy.

\section{PLL-pAra 2 Vaccination Resulted in Enhanced Migration of CD207+ DCs to dLNs}

After injection with DNA vaccine, local cells might take up the DNA, synthesize the protein encoded by the DNA [25], then express the protein, and present it to APCs. APCs would be stimulated by the antigen and migrate to lymph nodes and present the antigen to $\mathrm{T}$ cells, allowing the adaptive immunity to develop. To evaluate the efficiency of DNA vaccine immunization, we analyzed the number of CD207+ DCs in dLNs (the gating strategy is shown in online suppl. Fig. S2) after intradermal immunization with the pAra h 2 or PLL-pAra h 2 for 3 times at weekly intervals. We found that the relative numbers of CD207+ cells gated from CD11b+ cells in dLNs were increased in the PLL-pAra h 2, pAra h 2, or Ara h 2 groups (Fig. 4a, b). The absolute numbers of
$\mathrm{CD} 11 \mathrm{~b}+\mathrm{EGFP}+$ in dLNs were increased in the PLL-pAra h 2, pAra h 2, or Ara h 2 groups (Fig. 4c). The PLL-pAra $\mathrm{h} 2$ group showed higher percentages and absolute numbers than the pAra h 2 or the Ara h 2 group. Thus, immunization with pAra $\mathrm{h} 2$ vaccine induced CD207+ DCs to migrate into dLNs, which was promoted by PLL modification.

\section{Increased Treg Cell Induction in dLNs and Spleen by}

PLL-pArah 2 Vaccine

Previous studies have demonstrated that Treg cells can confer significant protection against allergy by suppressing Th2 responses. We determined the relative number of CD4+CD25+Foxp3+ Treg cells in local mouse dLNs and spleen of all groups. The results showed that there were significantly increased relative numbers of Treg cells in the pAra $\mathrm{h} 2$ and the PLL-pAra h 2 group compared with the PBS, PLL, or mock DNA control group in local dLNs (Fig. 5a, b). Ara h 2 protein-immunized mice showed similar relative numbers of Treg cells as control groups. Moreover, the PLL-pAra h 2 group had a higher percent- 


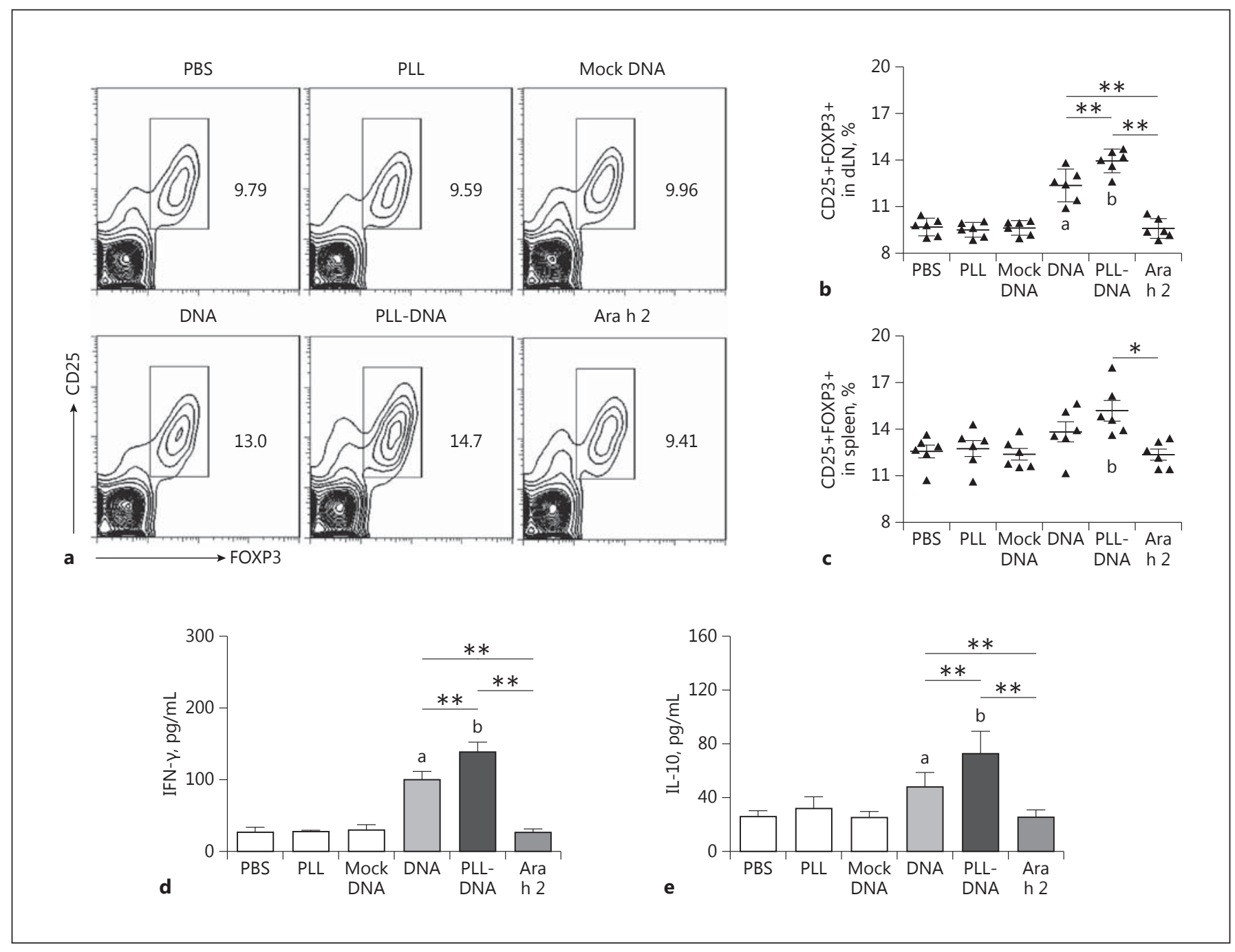

Fig. 5. Induction of Treg and cytokine production after DNA vaccination. BALB/c mice were given 3 intradermal weekly injections with PBS, PLL, mock DNA, DNA, PLL-DNA, or Ara h 2 protein, and 3 days after the last immunization, cells from skin dLNs and the spleen were prepared and analyzed. a Representative FACS results showing CD25+FOXP3+ cells gated from CD4+ cells in dLNs. b Statistic results of the relative number of

age of Treg cells than the pAra $\mathrm{h} 2$ group. The relative numbers of Treg cells in the spleen had a similar trend (Fig. 5c). These data indicated that peanut DNA vaccine induced the production of Treg cells and modification with PLL enhanced this effect.

\section{PLL-pAra $h 2$ Induced More IFN- $\gamma$ and IL-10}

Production by Splenocytes

After immunization of BALB/c mice with PLL-pAra h 2 or pAra h 2, mouse splenocytes were prepared and cul-
$\mathrm{CD} 4+\mathrm{CD} 25+\mathrm{FOXP} 3+$ cells in dLNs. c Relative numbers of $\mathrm{CD} 25+\mathrm{FOXP} 3+$ cells gated from CD4+ cells in the spleen. Concentration of IFN- $\gamma$ (d) and IL-10 (e) in culture supernatant of splenocytes incubated with Ara h 2. Data represent 1 of 3 independent experiments with 6 mice per group. Means \pm SD. ${ }^{*} p<0.05$, $* p<0.05$, vs. PBS, PLL, or mock DNA. tured for 5 days with Ara h 2. Cytokines, including IL-4, IL-5, IL-10, IL-22, and IFN- $\gamma$, in the culture supernatants were examined by ELISA. There were significantly increased levels of IFN- $\gamma$ (Fig. 5d) and IL-10 (Fig. 5e) in the culture from the pAra $\mathrm{h} 2$ group compared with the PBS, PLL, mock DNA, or Ara h 2 groups. PLL-pAra h 2-treated mice exhibited even more production of IFN- $\gamma$ and IL-10 than the pAra $\mathrm{h} 2$ group. However, almost no IL-4, IL-5, or IL- 22 could be detected, and there were no changes among different groups. 


\section{Discussion}

Peanut allergy, which affects around $1 \%$ of the population in western countries, is among the most severe food allergies and can cause life-threatening clinical manifestations, including death. In contrast to the expanding array of treatments available for inhalant and cutaneous allergic disorders, currently, the only available treatment for anaphylaxis following accidental ingestions is rapid self-administration of injectable epinephrine. Although oral immunotherapy has gained great success for the treatment of patients with food allergy in the past several years, for severe food allergy, oral immunotherapy is still very dangerous as trace amounts of peanut allergen would lead to anaphylaxis. Allergen-free DNA vaccine has been recognized as a promising alternative immunotherapy for severe food allergy because of its safety and efficacy. However, the major hurdle for these and all allergen gene vaccination approaches has been the poor efficiency of DNA transfer and subsequent gene expression in allergic disease models. In the present study, we used PLL to modify the peanut gene vaccine to enhance the efficiency of immunotherapy. The results showed that PLL modifications of DNA changed the polymerization status of the DNA, and intradermal injection with PLL-pAra $h 2$ prevented the development of allergen-specific IgG1, IgG2a, and total IgE after Ara h 2 protein sensitization more efficiently than pAra $h 2$, and inhibited the symptoms of peanut protein-induced anaphylaxis. Most importantly, intradermal injection with PLL-pAra $\mathrm{h} 2$ resulted in better therapeutic effects than pAra $\mathrm{h} 2$ on established peanut allergy, as evidenced by the decreased level of Ara $\mathrm{h} 2$-specific antibodies. Immunization with PLL-pAra h 2 induced increased numbers of CD207+ DC, Treg cells and increased levels of IFN- $\gamma$ and IL-10 production. Collectively, our study showed that pDNA pretreated with PLL had superior efficiency versus naked pDNA, and PLL modification could enhance the efficiency of peanut gene vaccination, providing a possible strategy for future clinical applications.

Among the many strategies tested to improve the potency of DNA vaccines, PLL is simple and efficient [26]. Polylysine is a biocompatible, nontoxic polyamino acid with a broad spectrum of usage [20]. PLLs with molecular weights of 15,000-30,000 were usually used in the study of DNA modification, as shorter-chain PLL was shown to have low binding efficiency with DNA [27]. PLL can condense elongated pDNA into uniform toroidal and rodshaped structures, and the average size of polyplexes was approximately $200 \mathrm{~nm}$ [27]. Previous studies demonstrated that Th1 responses could be induced when large vesicles were phagocytized by macrophages [28], and pDNA complexes formed by PLL showed better effects in transfection than naked pDNA in vitro [29]. Several studies showed that injection of pDNA can induce substantial expression of protein in vivo and elicit immune responses against the protein expressed $[9,30]$. The mechanisms that may explain how PLL improved the efficiency of DNA vaccine in vivo are described in the following. First, DNA condensation is an important factor in conferring nuclease resistance to DNA in polyplexes. Second, inclusion of DNA into polyplexes would enhance DNA binding to local cell membranes due to the cationic polyplexes and the negatively charged host cell membrane. Third, Ara $\mathrm{h} 2$ would become an intracellular antigen that can be processed and presented on major histocompatibility class (MHC)-I molecules or both MHC-I and MHC-II molecules on APCs. Besides the efficacy, the safety of PLL has also been proven in rodents [31]. Thus, the current use of PLL in drug delivery shed light on the potential application of PLL as an optimal vehicle for DNA delivery.

Multiple mechanisms may be involved in DNA vaccination in allergic diseases. Shifting from a Th2-type response towards a Th1-biased response has been demonstrated in anti-allergy DNA vaccine studies [32]. Most of the previous articles showed exaggerated Th1 responses after allergen challenge in sensitized mice [14,33]. In our experiment, there was a modest increase in the IFN- $\gamma$ level after pAra h 2 or PLL-pAra h 2 vaccination. This result indicated that Th1 responses were induced and might counterbalance the subsequent allergen-induced sensitization.

The induction of Treg cells and IL-10 has been shown to play an important role in maintaining peripheral T-cell tolerance, which is essential for normal immune responses and successful immunotherapy of allergic disorders $[32,34,35]$. We found that there were increased relative numbers of CD4+CD25+FOXP3+ cells in both the dLNs and the spleen in PLL-pAra $\mathrm{h}$ 2-treated mice, which were much higher than those of pAra $\mathrm{h} 2$-treated mice. There was also increased IL-10 secretion in splenocytes of PLLpAra h 2-treated mice. It is generally accepted that type 1 regulatory $\mathrm{T}(\mathrm{Tr} 1)$ cells play an essential role in the induction and maintenance of healthy immune responses to allergens. Actually, both Tr1 and CD4+CD25+FOXP3+ Tregs coexist and overlap in many immune tolerance-related situations, and the expression of the anti-inflammatory cytokine IL-10 can be induced by FOXP3 [36]. Increased proportion of either $\operatorname{Tr} 1$ or $\mathrm{CD} 4+\mathrm{CD} 25+\mathrm{FOXP} 3+$ Treg cells is associated with the restoration of tolerance [37]. In particular, IL-10 can be synthesized by activated 
and antigen-specific Treg and Breg cell populations. IL10 directly inhibits T-cell activation through suppression of CD28- and ICOS-dependent T-cell costimulation [38]. In addition, IL-10 inhibits the production of proinflammatory cytokines, chemokines, and chemokine receptors as well as the expression of MHC-II and costimulatory molecules CD80 and CD86 on monocytes/macrophages and DCs. Thus, our results found that both CD4+CD25+FOXP3+ Treg cells and IL-10 were induced by PLL-modified gene vaccine, indicating that multiple mechanisms were involved in the induction of immune regulation by DNA vaccine.

In DNA vaccination, DCs initiate immune responses and play a central role in the priming and amplification of adaptive immune responses after DNA vaccination. In our study, intradermal injection of pAra $\mathrm{h} 2$ resulted in increased numbers of CD207+ DCs in dLNs and PLL modification enhanced this effect. Blood-derived langerin + DCs can be distinguished from migratory Langerhans cells and dermal langerin + DCs by their low expression of CD207(EGFP) [39]. The uptake of PLL-pAra h 2 complexes by CD207+ DCs may promote the migration of CD207+ DCs to dLNs and induce more Treg cells and suppress peanut allergy. Altogether, the results presented here suggested that immunization with PLL-pAra $h 2$ promoted the migration of CD207+ DCs to dLNs and enhanced the production of Treg cells, IL-10, and induction of Th1 responses, to prevent or reverse Th2-type immune responses.
There were several limitations in our experiments. First, it is noteworthy that there are strain-dependent variations in the development of allergic responses among different mouse strains and the effect of DNA-based immunotherapy might be strain dependent and not universally effective in reversing IgE-mediated food hypersensitivity in human subjects [40]. Second, our peanut allergy model established in BALB/c mice is not through a physiological route of sensitization, and the usage of alum in the food allergy model is still in doubt because of its nonphysiological nature [41]. Furthermore, the recent expansion of the repertoire of therapeutic nucleic acids from classical DNA gene transfer constructs to many other gene expression and protein-modulating nucleic acids such as mRNA, miRNA, or siRNA is expected to generate an additional boost for further optimization of polymeric delivery systems.

\section{Acknowledgments}

This work was supported by the National Natural Science Foundation of China (grant Nos. 81273320, 81271750, 81300928, 81573038, and 81573045).

\section{Disclosure Statement}

There are no conflicts of interest.

\section{References}

1 Nwaru BI, Hickstein L, Panesar SS, Roberts G, Muraro A, Sheikh A: Prevalence of common food allergies in Europe: a systematic review and meta-analysis. Allergy 2014;69:9921007.

2 Bublin M, Breiteneder H: Developing therapies for peanut allergy. Int Arch Allergy Immunol 2014;165:179-194.

3 Wood RA: Food allergen immunotherapy: current status and prospects for the future. J Allergy Clin Immunol 2016;137:973-982.

4 Du Toit G, Roberts G, Sayre PH, Bahnson HT, Radulovic S, Santos AF, Brough HA, Phippard D, Basting M, Feeney M, Turcanu V, Sever ML, Gomez LM, Plaut M, Lack G: Randomized trial of peanut consumption in infants at risk for peanut allergy. N Engl J Med 2015;372:803-813.

5 Du Toit G, Sayre PH, Roberts G, Sever ML, Lawson K, Bahnson HT, Brough HA, Santos AF, Harris KM, Radulovic S, Basting M, Turcanu V, Plaut M, Lack G; Immune Tolerance
Network LEAP-On Study Team: Effect of avoidance on peanut allergy after early peanut consumption. N Engl J Med 2016;374:14351443 .

6 Wavrin S, Bernard H, Wal J, Adel-Patient K: Cutaneous or respiratory exposures to peanut allergens in mice and their impacts on subsequent oral exposure. Int Arch Allergy Immunol 2014;164:189-199.

7 Jones SM, Agbotounou WK, Fleischer DM, Burks AW, Pesek RD, Harris MW, Martin L, Thebault C, Ruban C, Benhamou PH: Safety of epicutaneous immunotherapy for the treatment of peanut allergy: a phase 1 study using the Viaskin patch. J Allergy Clin Immunol 2016;137:1258-1261.

8 Hochreiter R, Stepanoska T, Ferreira F, Valenta R, Vrtala S, Thalhamer J, Hartl A: Prevention of allergen-specific IgE production and suppression of an established Th2-type response by immunization with DNA encoding hypoallergenic allergen derivatives of Bet v 1, the major birch-pollen allergen. Eur J Immunol 2003;33:1667-1676.

9 Hsu CH, Chua KY, Tao MH, Lai YL, Wu HD, Huang SK, Hsieh KH: Immunoprophylaxis of allergen-induced immunoglobulin E synthesis and airway hyperresponsiveness in vivo by genetic immunization. Nat Med 1996;2:540-544.

10 Ludwig-Portugall I, Montermann E, Kremer A, Reske-Kunz AB, Sudowe S: Prevention of long-term IgE antibody production by gene gun-mediated DNA vaccination. J Allergy Clin Immunol 2004;114:951-957.

11 Roy K, Mao HQ, Huang SK, Leong KW: Oral gene delivery with chitosan-DNA nanoparticles generates immunologic protection in a murine model of peanut allergy. Nat Med 1999;5:387-391.

12 Peng HJ, Su SN, Chang ZN, Chao PL, Kuo SW, Tsai LC: Induction of specific Th1 responses and suppression of IgE antibody formation by vaccination with plasmid DNA encoding Der f 11. Vaccine 2002;20:1761-1768. 
13 Raz E, Tighe H, Sato Y, Corr M, Dudler JA, Roman M, Swain SL, Spiegelberg HL, Carson DA: Preferential induction of a Th1 immune response and inhibition of specific IgE antibody formation by plasmid DNA immunization. Proc Natl Acad Sci USA 1996;93:51415145.

14 Hartl A, Hochreiter R, Stepanoska T, Ferreira F, Thalhamer J: Characterization of the protective and therapeutic efficiency of a DNA vaccine encoding the major birch pollen allergen Bet v 1a. Allergy 2004;59:65-73.

15 Zhou B, Ensell M, Zhou Y, Nair U, Glickstein J, Kermany MH, Cai Q, Cai C, Liu W, Deng YP, Kakigi A, Barbieri M, Mora M, Kanangat S, Yoo TJ: Prevention and treatment of DNA vaccine encoding cockroach allergen Bla $\mathrm{g} 1$ in a mouse model of allergic airway inflammation. Allergy 2012;67:166-174.

16 Fissolo N, Costa C, Nurtdinov RN, Bustamante MF, Llombart V, Mansilla MJ, Espejo C, Montalban X, Comabella M: Treatment with MOG-DNA vaccines induces CD4+CD25+FoxP3+ regulatory $\mathrm{T}$ cells and up-regulates genes with neuroprotective functions in experimental autoimmune encephalomyelitis. J Neuroinflammation 2012; 9:139.

17 Li L, Saade F, Petrovsky N: The future of human DNA vaccines. J Biotechnol 2012;162: 171-182.

18 Lächelt U, Wagner E: Nucleic acid therapeutics using polyplexes: a journey of 50 years (and beyond). Chem Rev 2015;115:1104311078.

19 Behnecke A, Li W, Chen L, Saxon A, Zhang $\mathrm{K}$ : IgE-mediated allergen gene vaccine platform targeting human antigen-presenting cells through the high-affinity IgE receptor. J Allergy Clin Immunol 2009;124:108-113.

20 Shi C, He Y, Feng X, Fu D: $\varepsilon$-Polylysine and next-generation dendrigraft poly-L-lysine: chemistry, activity, and applications in biopharmaceuticals. J Biomater Sci Polym Ed 2015;26:1343-1356.

21 Porterfield HS, Murray KS, Schlichting DG, Chen X, Hansen KC, Duncan MW, Dreskin SC: Effector activity of peanut allergens: a critical role for Ara h 2, Ara h 6, and their variants. Clin Exp Allergy 2009;39:1099-1108.

22 Kulis M, Chen X, Lew J, Wang Q, Patel OP, Zhuang Y, Murray KS, Duncan MW, Porterfield HS, W Burks A, Dreskin SC: The 2S albumin allergens of Arachis hypogaea, Ara h 2 and Ara h 6, are the major elicitors of anaphylaxis and can effectively desensitize peanutallergic mice. Clin Exp Allergy 2012;42:326336.

23 Chang LM, Song Y, Li X, Sampson HA, Masilamani M: Dietary elimination of soybean components enhances allergic immune response to peanuts in $\mathrm{BALB} / \mathrm{c}$ mice. Int Arch Allergy Immunol 2015;166:304-310.

24 Li W, Zhang Z, Saxon A, Zhang K: Prevention of oral food allergy sensitization via skin application of food allergen in a mouse model. Allergy 2012;67:622-629.

25 Raz E, Carson DA, Parker SE, Parr TB, Abai AM, Aichinger G, Gromkowski SH, Singh M, Lew D, Yankauckas MA, et al: Intradermal gene immunization: the possible role of DNA uptake in the induction of cellular immunity to viruses. Proc Natl Acad Sci USA 1994;91: 9519-9523.

26 Saade F, Petrovsky N: Technologies for enhanced efficacy of DNA vaccines. Expert Rev Vaccines 2014;11:189-209.

27 Kwoh DY, Coffin CC, Lollo CP, Jovenal J, Banaszczyk MG, Mullen P, Phillips A, Amini A, Fabrycki J, Bartholomew RM, Brostoff SW, Carlo DJ: Stabilization of poly-L-lysine/DNA polyplexes for in vivo gene delivery to the liver. Biochim Biophys Acta 1999;1444:171190.

28 Desmedt M, Rottiers P, Dooms H, Fiers W, Grooten J: Macrophages induce cellular immunity by activating Th1 cell responses and suppressing Th2 cell responses. J Immunol 1998; 160:5300-5308.

29 Pouton CW, Lucas P, Thomas BJ, Uduehi AN, Milroy DA, Moss SH: Polycation-DNA complexes for gene delivery: a comparison of the biopharmaceutical properties of cationic polypeptides and cationic lipids. J Control Release 1998;53:289-299.

30 Wolff JA, Malone RW, Williams P, Chong W, Acsadi G, Jani A, Felgner PL: Direct gene transfer into mouse muscle in vivo. Science 1990;247:1465-1468.

31 Hiraki J, Ichikawa T, Ninomiya S, Seki H, Uohama K, Seki H, Kimura S, Yanagimoto Y, Barnett JJ: Use of ADME studies to confirm the safety of epsilon-polylysine as a preservative in food. Regul Toxicol Pharmacol 2003; 37:328-340

32 Pfutzner W: Allergen-specific tolerance induction: of mice and men. Int Arch Allergy Immunol 2015;166:81-83.
33 Li X, Srivastava K, Grishin A, Huang C, Schofield B, Burks W, Sampson HA: Persistent protective effect of heat-killed Escherichia coli producing engineered recombinant peanut proteins in a murine model of peanut allergy. J Allergy Clin Immunol 2003;112:159167.

34 Akdis CA, Akdis M: Mechanisms of immune tolerance to allergens: role of IL-10 and Tregs. J Clin Invest 2014;124:4678-4680.

35 Yamamoto T, Fujiwara K, Tsubota Y, Kageyama-Yahara N, Hayashi S, Kadowaki M: Induction of regulatory T cells as a novel mechanism underlying the therapeutic action of kakkonto, a traditional Japanese herbal medicine, in a murine food allergy model. Int Arch Allergy Immunol 2016;169:146-156.

36 Pellerin L, Jenks JA, Bégin P, Bacchetta R, Nadeau KC: Regulatory T cells and their roles in immune dysregulation and allergy. Immunol Res 2014;58:358-368.

37 Syed A, Garcia MA, Lyu S, Bucayu R, Kohli A Ishida S, Berglund JP, Tsai M, Maecker $\mathrm{H}$, O'Riordan G, Galli SJ, Nadeau KC: Peanut oral immunotherapy results in increased antigen-induced regulatory $\mathrm{T}$-cell function and hypomethylation of forkhead box protein 3 (FOXP3). J Allergy Clin Immunol 2014;133: 500-510.

38 Taylor A, Akdis M, Joss A, Akkoc T, Wenig R, Colonna M, Daigle I, Flory E, Blaser K, Akdis CA: IL-10 inhibits CD28 and ICOS costimulations of T cells via src homology 2 domaincontaining protein tyrosine phosphatase 1 . J Allergy Clin Immunol 2007;120:76-83.

39 Kissenpfennig A, Henri S, Dubois B, LaplaceBuilhe $\mathrm{C}$, Perrin $\mathrm{P}$, Romani N, Tripp $\mathrm{CH}$, Douillard P, Leserman L, Kaiserlian D, Saeland S, Davoust J, Malissen B: Dynamics and function of Langerhans cells in vivo: dermal dendritic cells colonize lymph node areas distinct from slower migrating Langerhans cells. Immunity 2005;22:643-654.

40 Li X, Huang CK, Schofield BH, Burks AW, Bannon GA, Kim KH, Huang SK, Sampson HA: Strain-dependent induction of allergic sensitization caused by peanut allergen DNA immunization in mice. J Immunol 1999;162: 3045-3052.

41 Parvataneni S, Gonipeta B, Acharya HG, Gangur V: An adjuvant-free mouse model of transdermal sensitization and oral elicitation of anaphylaxis to shellfish. Int Arch Allergy Immunol 2015;168:269-276. 